\title{
Factors Associated with Exposure to Passive Smoking among 12-18 year-old Students in Athens and Thessaloniki, Greece
}

\author{
Andreas S Lappas ${ }^{1,2}$, Anna S Tzortzi ${ }^{2}$, Efstathia M Konstantinidi' ${ }^{1,2}$ Niki L Dimou $^{3}$, Panagiotis Behrakis $^{1,2}$
}

\begin{abstract}
INTRODUCTION Passive-smoking is a major, preventable cause of disease, disability and death. It is estimated that the majority of the world's population is still living in countries not fully covered by smoke-free public health regulations and Greece is unfortunately one of them. The aim of our study, conducted in October 2014, was to provide up to date information regarding determinants of exposure to passive smoking among the student population of the two biggest Greek cities.

METHODS Our survey was conducted on a representative sample of middle and high school students (1803 in total, 810 boys and 992 girls), living in the two biggest cities of Greece. A questionnaire was developed to estimate the exposure of students to passive-smoking. Relative frequencies were calculated for all the questions and a Pearson x2-test was used to evaluate the potential association of several variables with gender, age and smoking status. Logistic regression analysis were also applied to evaluate the association between social influences and the likelihood of being exposed to passive smoking.

RESULTS A total of $86.7 \%$ of youth were exposed to passive-smoking during the 30 days preceding the survey. Daily exposure during the past 7 days was reported by $20.2 \%$ of the students. The highest rates of exposure were reported in cafes (61.2\%), home (43.7\%) and school (37.2\%). Gender, age, smoking status, and the smoking habits of parents, siblings and friends, but also the sight of peers and teachers smoking inside the school campus, were significant determinants of students' exposure to passive smoking.

concLusions Passive-smoking exposure is prevalent among the student population in Greece, despite the New Anti-Smoking Legislation that came into effect in July 2009. Our findings indicate that enforcement of the law and additional public health initiatives must be implemented.
\end{abstract}

AFFILIATION

1 Biomedical Research

Foundation of the Academy of Athens, Greece

2 Smoking and lung cancer research center, Hellenic Cancer Society, Greece

3 Department of computer science and biomedical informatics, University of Thessaly, Greece

\section{CORRESPONDENCE TO}

Lappas A. Biomedical Research Foundation of the Academy of Athens (BRFAA), 4 Soranou Ephessiou st. 115 27, Athens, Greece, andreaslappaswork@ gmail.com

\section{KEY WORDS}

passive smoking, students, Greece

\section{INTRODUCTION}

Exposure to passive-smoking is a major, preventable cause of disease, disability and death, with consequent huge economic costs $^{1}$. Undoubtedly, children and adolescents are the main victims of passive-smoking, as they are at considerable risk of developing cognitive impairment ${ }^{2}$, cancer ${ }^{3,4}$, asthma, acute lower respiratory tract infections, but also irreversibly impaired lung function ${ }^{5}$. Furthermore, it is estimated that exposure to passive-smoking kills 600,000 children per year worldwide ${ }^{6}$.

Policies towards the prevention of exposure to passivesmoking have been implemented in many developed countries. However, it is estimated that $93 \%$ of the world's population is still living in countries not fully covered by smoke-free public health regulations ${ }^{6}$. Unfortunately, Greece is one of them. Previous studies (2004-2005) detected extremely high prevalence of exposure to passive smoking among adolescent students ${ }^{7,8}$. In 2004-2005, nearly 9 out of 10 Greek students aged 13-15 years were exposed to passive-smoking either at home ${ }^{7}$ or outside . $^{8}$

Despite the above, significant initiatives have been taken since the last epidemiological data were published. First and foremost, in May 2006, Greece ratified the WHO Framework Convention on Tobacco Control (FCTC), which was a significant motivation for many public health initiatives. The most important initiative was the new Greek Anti-smoking Legislation, which came into effect in July 2009, clearly stating that it is against the law to smoke in any indoor public places. Such important interventions have created optimism regarding the restriction and, ideally, the elimination of exposure to passive-smoking in public places.

The aim of our study was to provide up-to-date information regarding exposure to passive-smoking among high school students in the two biggest Greek cities in 2014. 


\section{METHODS}

\section{Study Background}

This project was conducted in the framework of the HEART II project. HEART II is an initiative that brings together the Greek ministries of Health and Education, the Biomedical Research Foundation of the Academy of Athens and the Hellenic Cancer Society with the aim to produce research, policies and interventions devoted to tobacco prevention and cessation in Greece. The present study represents baseline data of a large-scale national survey entitled "I learn the truth; I say no to cigarettes". The Department of Research, Validation and Educational Technology of the Pedagological Institute approved the study (protocol No. 63377/G2/24-04-2014).

\section{Sampling Procedures}

Our survey was conducted on a representative sample of middle and high school students living in the two biggest cities of Greece, Athens and Thessaloniki. Our methodology was based on a two-stage stratified clustered design with schools as the primary sampling units and school classes as the secondary units. A listing of all public and private middle or high schools by grade in Athens and Thessaloniki for the 2013-2014 school years was used as the sampling frame. Schools of special education, such as music and vocational schools, were excluded. The sampling design featured three levels of stratification: city, regional directorate of secondary education and grade. Within each stratum and for each grade (grades 1-3 in all middle or high schools), schools were selected with probability proportional to their size, with the selection done independently for each grade so that some schools may have provided classes at more than one grade. The selection of the secondary sampling units (school classes) was conducted by field staff that randomly selected one class in the desired grade. All students attending school the day that the survey was conducted were eligible to participate.

\section{Participants}

A total of 1802 students participated in the study. Student participation was voluntary and anonymous, while their parents signed an informed consent form. Of the respondents, 794 were middle-school students and 1008 were highschool students ( 810 boys and 992 girls in total). All students of each selected class returned a completed selfanswered questionnaire. No questionnaire was excluded due to incompleteness or incorrect responses (participation rate $=100 \%$ ).

\section{Measures and Definitions}

We developed a short questionnaire, partially adopting the design of Global Youth Tobacco Survey (GYTS) ${ }^{9}$. Slightly modified elements of our own questionnaire design compared to the GYTS are outlined below:

1. We evaluated exposure both at home and outside of the home during the preceding 30 days and the preceding 7 days.

2. We added a question in order to include data on placespecific relative frequencies.

3. We added questions regarding smoking habits and attitudes of the students' social environment towards smoking, in order to evaluate them as determinants of exposure to passive-smoking. This approach has been applied before by Rachiotis et al. ${ }^{8}$, using parental and friends' smoking habits as determinants of exposure among 12-17 year-old students. In addition to the above we assessed the effect of students viewing of their peers and teachers smoking inside the school area, as potential determinants.

4. Our sample's age range (12 -18 year-old students) was wider in comparison to the GYTS: students aged $13-15^{7}$ and 11-17 years ${ }^{8}$.

We included data on exposure to passive-smoking at home and public indoor places. Exposure was evaluated using two standards: Exposure during the 30 days preceding the survey, and frequency of exposure (in days) during the 7 days preceding the survey. Exposure to passive smoking was based on the question: "Have you been in an indoor place (including your home) where people were smoking during the last 30 days?". The questionnaire design was evaluated for consistency and stability by the Technical Report Team of the Biomedical Research Foundation of the Academy of Athens in October 2013 (report number 1.2) ${ }^{10}$. With regards to smoking status, non-smokers were those who did not smoke cigarettes for the past 30 days, occasional smokers were those who smoked less than 20 cigarettes the past 30 days, while regular smokers were those who smoked more than 20 cigarettes during the past 30 days.

\section{Statistical Analysis}

Frequencies and relative frequencies were calculated for all responses. A Pearson x2- test was used to evaluate the potential association of several variables with age, gender and smoking status. Multiple logistic regression analysis was applied to evaluate the association between social influences and the likelihood of being exposed to passive-smoking. The analysis accounted for the potential confounding effect of gender and age. For all analyses performed, the statistical package Stata 10 (Stata Corporation, College Station, Texas, USA) was used, while statistically significant results were declared for those with $\mathrm{p}<0.05$. 


\section{RESULTS}

Table 1 summarizes our findings regarding exposure to passive smoking at home and public indoor places during the 30 days preceding the survey.

According to our results, $86.7 \%$ of the students were exposed to passive smoking both at home and other areas during the 30 days preceding the survey. Increasing age was associated with higher exposure $(\mathrm{p}<0.001)$. We also found that smokers were significantly more exposed than non-smokers $(p<0.001)$ to passive smoking. In regard to the specific indoor places of exposure during the 30 days preceding the study, the highest rates were observed for cafes and home, followed by exposure at school, bar, night-club, friend's house and restaurant.

Gender was associated with place of exposure $(\mathrm{p}=0.004)$ : males were more exposed at bars and night-clubs compared with females, whereas females were more exposed at home, friend's house, school and cafes. Additionally, age was related with exposure rates at specific places $(p<0.001)$. Exposure at a friend's house, school, cafes, restaurant, bars and nightclubs increased with increasing age, and there was also an upward trend in exposure rates at home with increasing age. Table 2 summarizes our results on the frequency of exposure to passive smoking during the 7 days preceding the survey. Daily exposure during the preceding 7 days was reported by $20,2 \%$ of the students. Frequency of exposure was significantly lower among males compared to females $(p<0.001)$. We also found a rise in exposure frequency with increasing age $(p<0.001)$. Finally, we found that smokers were exposed more frequently compared to non-smokers during the previous week $(p<0.001)$. With regards to determinants of passivesmoking exposure, current smoking status, parental, siblings' and friends' smoking habits and the sight of peers and teachers smoking inside the school grounds were significant determinants of exposure to passive smoke.

Table 3 presents the results of a logistic regression model, describing the relationship between exposure to passive smoking during the 30 days preceding the study (outcome variable) and the smoking habits of parents, siblings, friends, peers, and teachers (covariates). The analysis accounted for the potential confounding effect of gender and age. Students whose parents smoke were more than 2 times likely to be exposed to passive smoking $(\mathrm{OR}=2.074,95 \% \mathrm{CI}=1.325-3.244, \mathrm{p}=0.001)$. Students with siblings who smoke were almost 3 times likely to be exposed ( $\mathrm{OR}=2.808,95 \% \mathrm{CI}=1.184-6.657, \mathrm{p}=0.019)$. Students with no friends that are smokers were at a significantly

Table 1: Exposure to passive smoking in indoor places among middle and high school students living in Athens and Thessaloniki, Greece 2014.

\begin{tabular}{|c|c|c|c|c|c|c|c|c|c|c|}
\hline & & \multicolumn{2}{|c|}{ Exposed } & \multicolumn{2}{|c|}{ Place of exposure } & & & & & \multirow[t]{2}{*}{ p value } \\
\hline & & Home & Cafe & School & Bar & Vight club & $\begin{array}{l}\text { Friend's } \\
\text { house }\end{array}$ & Restaurant & Other & \\
\hline \multicolumn{11}{|c|}{ Gender } \\
\hline Males & $86.9 \%$ & $40.7 \%$ & $58.6 \%$ & $36.7 \%$ & $30.9 \%$ & $26.8 \%$ & $21.5 \%$ & $22.3 \%$ & $17.5 \%$ & $p=0.031$ \\
\hline Females & $86.5 \%$ & $46.1 \%$ & $63.3 \%$ & $37.6 \%$ & $22.4 \%$ & $18.8 \%$ & $22.9 \%$ & $21.2 \%$ & $18.2 \%$ & \\
\hline \multicolumn{11}{|c|}{ Age (years) } \\
\hline 12 & $71.8 \%$ & $40.8 \%$ & $32.4 \%$ & $26.8 \%$ & $5.6 \%$ & $4.2 \%$ & $5.6 \%$ & $14.1 \%$ & $2.8 \%$ & $p<0.001$ \\
\hline 13 & $76.5 \%$ & $36.1 \%$ & $45 \%$ & $21.8 \%$ & $11.8 \%$ & $7.1 \%$ & $8.4 \%$ & $23.1 \%$ & $5 \%$ & \\
\hline 14 & $80.3 \%$ & $33.8 \%$ & $45.7 \%$ & $26 \%$ & $9.3 \%$ & $10 \%$ & $15.2 \%$ & $23 \%$ & $3.3 \%$ & \\
\hline 15 & $89.5 \%$ & $45.8 \%$ & $61.4 \%$ & $34.7 \%$ & $25.3 \%$ & $22 \%$ & $18.8 \%$ & $20.6 \%$ & $7.9 \%$ & \\
\hline 16 & $87.3 \%$ & $43 \%$ & $69.4 \%$ & $42.7 \%$ & $28.8 \%$ & $24.8 \%$ & $21.8 \%$ & $20.3 \%$ & $22.4 \%$ & \\
\hline 17 & $92.1 \%$ & $50 \%$ & $72 \%$ & $45.3 \%$ & $38.6 \%$ & $31.9 \%$ & $30.2 \%$ & $20.5 \%$ & $32.2 \%$ & \\
\hline$\geq 18$ & $96.2 \%$ & $51.6 \%$ & $75.1 \%$ & $\begin{array}{l}51.2 \% \\
44.1 \%\end{array}$ & $39.4 \%$ & $42.3 \%$ & $26.5 \%$ & $34.7 \%$ & & \\
\hline \multicolumn{11}{|c|}{ Smoking Status } \\
\hline Regular & $96.2 \%$ & $63.1 \%$ & $87.3 \%$ & $69.4 \%$ & $59.9 \%$ & $55.4 \%$ & $63.1 \%$ & $33.8 \%$ & $45.2 \%$ & $p<0.001$ \\
\hline Occasional & $97.1 \%$ & $60.6 \%$ & $86.5 \%$ & $57.6 \%$ & $52.4 \%$ & $54.9 \%$ & $45.3 \%$ & $27.1 \%$ & $32.4 \%$ & \\
\hline $\begin{array}{l}\text { Non- } \\
\text { smokers }\end{array}$ & $84.4 \%$ & $39.8 \%$ & $55.6 \%$ & $31.2 \%$ & $19.5 \%$ & $15.6 \%$ & $14.9 \%$ & $19.8 \%$ & $13.4 \%$ & \\
\hline $\begin{array}{l}\text { Total } \\
(100 \%)\end{array}$ & $86.7 \%$ & $43.7 \%$ & $61.2 \%$ & $37.2 \%$ & $26.2 \%$ & $22.4 \%$ & $21.3 \%$ & $21.7 \%$ & $17.9 \%$ & \\
\hline
\end{tabular}


Research Article

Table 2: Exposure to passive smoking at home and in public places during the past week, among middle and high school students living in Athens and Thessaloniki, Greece, 2014

\begin{tabular}{|c|c|c|c|c|c|c|}
\hline Days & 07 & $1-27$ & $3-17$ & 567 & 77 & p value \\
\hline \multicolumn{7}{|c|}{ Gender } \\
\hline Males & $21.7 \%$ & $23.2 \%$ & $12.6 \%$ & $5.8 \%$ & $19 \%$ & \multirow[t]{2}{*}{$p<0.001$} \\
\hline Females & $19 \%$ & $16.7 \%$ & $12.5 \%$ & $7.6 \%$ & $21.2 \%$ & \\
\hline \multicolumn{7}{|c|}{ Age (years) } \\
\hline 12 & $39.4 \%$ & $16.9 \%$ & $9.9 \%$ & $2.8 \%$ & $11.3 \%$ & \multirow[t]{7}{*}{$p<0.001$} \\
\hline 13 & $29.4 \%$ & $23.9 \%$ & $8.4 \%$ & $3.4 \%$ & $12.2 \%$ & \\
\hline 14 & $27.1 \%$ & $19.7 \%$ & $8.9 \%$ & $3.3 \%$ & 11.25 & \\
\hline 15 & $20.2 \%$ & $19.5 \%$ & $12.6 \%$ & $8.7 \%$ & $17.7 \%$ & \\
\hline 16 & $17 \%$ & $20.9 \%$ & $12.4 \%$ & $8.5 \%$ & $22.4 \%$ & \\
\hline 17 & $14.4 \%$ & $19.1 \%$ & $15.3 \%$ & $9.7 \%$ & $24.3 \%$ & \\
\hline$\geq 18$ & $10.8 \%$ & 155 & $17.4 \%$ & $5.6 \%$ & $35.7 \%$ & \\
\hline \multicolumn{7}{|c|}{ Smoking Status } \\
\hline Regular & $1.3 \%$ & $6.4 \%$ & $14 \%$ & $9.6 \%$ & $55.4 \%$ & \multirow[t]{4}{*}{$p<0.001$} \\
\hline Occasional & $4.7 \%$ & $18.2 \%$ & $22.9 \%$ & $10 \%$ & $28.2 \%$ & \\
\hline Non-smokers & $24.3 \%$ & $21.3 \%$ & $11.2 \%$ & $6 \%$ & $15.5 \%$ & \\
\hline Total (100\%) & $20.2 \%$ & $19.6 \%$ & $12.5 \%$ & $6.8 \%$ & $20.2 \%$ & \\
\hline
\end{tabular}

Table 3: Logistic regression model evaluating the association between exposure to passive smoking and gender, age, smoking habits of parents, brothers sisters, friends, peers and teachers

\begin{tabular}{|c|c|c|c|c|}
\hline Covariate & OR & SE & $z, p$ value & $95 \% \mathrm{CI}$ \\
\hline \multicolumn{5}{|c|}{ Gender } \\
\hline Female & 1.003 & 0.226 & $z=0.012,0.991$ & $0.645-1.559$ \\
\hline \multicolumn{5}{|c|}{ Age (years) } \\
\hline $12-13 *$ & 1 & & & \\
\hline 14 & 0.739 & 0.234 & $z=-0.955,0.340$ & $0.397-1.375$ \\
\hline 15 & 1.705 & 0.695 & $z=1.308,0.191$ & $0.767-3.790$ \\
\hline 16 & 0.989 & 0.359 & $z=-0.030,0.976$ & $0.486-2.016$ \\
\hline 17 & 1.187 & 0.44 & $z=0.462,0.644$ & $0.574-2.455$ \\
\hline$\geq 18$ & 2.11 & 1.214 & $z=1.299,0.194$ & $0.684-6.515$ \\
\hline \multicolumn{5}{|c|}{ Are your parents smokers? } \\
\hline At least one of them is a smoker & 2.074 & 0.474 & $z=3.193,0.001$ & $1.325-3.244$ \\
\hline \multicolumn{5}{|c|}{ Are your brothers or sisters smokers? } \\
\hline Yes & 2.808 & 1.237 & $z=2.344,0.019$ & $1.184-6.657$ \\
\hline \multicolumn{5}{|c|}{ Are your friends smokers? } \\
\hline Over half of them are smokers* & 1 & & & \\
\hline Less than half of them are smokers & 0.461 & 0.208 & $z=-1.720,0.085$ & $0.190-1.114$ \\
\hline No one is a smoker & 0.166 & 0.071 & $z=-4.197,<0.001$ & $0.072-0.384$ \\
\hline \multicolumn{5}{|c|}{ Have you witnessed other students smoking inside school area? } \\
\hline Yes & 2.324 & 0.717 & $z=2.733,0.006$ & $1.269-4.253$ \\
\hline \multicolumn{5}{|c|}{ Have you witnessed your teachers smoking inside school area? } \\
\hline Yes & 1.973 & 0.465 & $z=2.886,0.004$ & $1.244-3.131$ \\
\hline
\end{tabular}

*Baseline category; Abbreviations: OR=Odds Ratio, SE=Standard Error, $95 \% \mathrm{Cl}=95 \%$ Confidence Interval 
lower risk of exposure in comparison to students with friends who smoke $(\mathrm{OR}=0.166,95 \% \mathrm{CI}=0.072-0.384, \mathrm{p}<0.001)$. The sight of peers' and teachers' smoking on school grounds were also significant determinants of exposure to passive smoking. Respondents who had witnessed their peers smoking were more than 2 times likely to be exposed to passive smoking during the past month $(\mathrm{OR}=2.324,95 \% \mathrm{CI}=1.269-4.253$, $\mathrm{p}=0.006$ ), students who had seen their teachers smoking were almost 2 times more likely to be exposed to passive smoking $(\mathrm{OR}=1.973,95 \% \mathrm{CI}=1.244-3.131, \mathrm{p}=0.004)$.

\section{DISCUSSION}

In this cross-sectional study we outlined the current rates of exposure to passive-smoking among students living in the two biggest cities of Greece. According to our results, more than $8 / 10$ students were exposed to passive smoking during the 30 days preceding the survey $(43.7 \%$ at home, $80.3 \%$ in other areas) and $59.1 \%$ of the students had been exposed at least once during the past week. Previous Greek studies (20042005) demonstrated exposure rates of $89.8 \%^{7}$ and $79.3 \%{ }^{8}$ at home, and $94.1 \%^{7}$ and $38.2 \%^{8}$ outside the home.

In regard to the rates of exposure outside the home, we demonstrated comparable or increased exposure rates relative to the results of the aforementioned Greek studies. This clearly indicates that there was a poor compliance to the new Greek Anti-smoking Legislation, which came into effect on July 1, 2009. Based on our results, it is clear that effective enforcement of the nationwide smoke-free legislation is imperative.

Another major finding of our study was the high prevalence of exposure inside the school area (37.2\%). In fact, rates of exposure at school were among the highest, following exposure at cafes and home. Furthermore, the sight of peers and teachers smoking inside the school area were significant determinants of exposure. These findings indicate the lack of tobacco-free school policies in Greece, which emerges as a top public health priority. Such policies could be assisted with integration of information on health hazards of tobacco products in the school curriculum, which will possibly make both teachers and students more aware of the consequences of smoking inside the school area.

Gender based stratification revealed slightly higher rates of exposure among males compared with females, which is consistent with the findings of surveys conducted in other countries ${ }^{11,12}$. However, in a former GYTS-based study conducted in Greece by Rachiotis et al. ${ }^{8}$, the authors reported that males were less likely to be exposed at home than females. We found that females were indeed significantly more exposed at home, but also at school, at friend's houses and cafes compared to males. Females reported a significantly higher frequency of exposure during the past week, higher rates of smoking among siblings and friends, and to a larger extent responded that they had witnessed their peers smoking on school grounds.

Gender differences could be caused either by real differences in exposure or by different perception of passive smoking. It is possible that males more frequently visit public indoor places where smoking is allowed and females may have a lower threshold in reporting exposure to passive smoking. However, this hypothesis could not be tested by our experimental design. Therefore, we suggest that further research is needed in order to evaluate the perceptions of exposure to passive smoking and their possible influence on the differences reported between male and female populations.

Age-based analysis indicated that, in general, increasing age was significantly associated with increased rates and frequency of exposure. This finding is in line with results of other relevant studies worldwide ${ }^{12,13}$. Exposure at home increased significantly with age, which is in agreement with the results of the study by Rachiotis et al. 2010. Exposure outside the home also increased with age. Especially among 18 year-olds we found that they were almost all exposed to passive-smoking (96.2\%) and the vast majority of them was exposed more than once a week. This finding is in contrast with the findings of Rachiotis et al. ${ }^{8}$, who reported that older adolescents (15-17 years-old) were less likely to be exposed outside home, explained by the assumption that those students purposely avoided exposure to passive smoking.

According to our analysis, increasing age was significantly related to increased frequency of exposure, higher rates of siblings and friends who smoke, but also with the increase in the number of students who had witnessed their peers and their teachers smoking on school grounds. Therefore, an opposing hypothesis emerges from our results: older students chose to be in places where smoking was allowed, since they chose to associate with smokers. However, it must be pointed out that, in our survey, increasing age was also associated with increasing rates of regular and occasional smoking. Hence, it stands to reason that older students, who were more likely to be smokers than younger students, chose to be in places where smoking was allowed.

We also stratified for smoking status, and identified that regular smokers were more exposed than occasional smokers, and the latter were more exposed than non-smokers, regardless of gender, age and place of exposure. Furthermore, we identified that smokers were more likely to have parents, siblings and friends who smoke, but they were also more likely to witness their peers and teachers smoking inside the school grounds. Therefore, we assume that, indeed, non- 
smokers chose to spend their time in places where smoking was forbidden, whereas smokers chose to act in the opposite way.

The aforementioned results indicate that one of the most efficient means of reducing passive-smoking exposure is the reduction of the burden of active smoking (both regular and occasional) among adolescents, but also among their parents and teachers. Therefore, public health authorities must produce more efficient policies towards tobacco prevention, and promote and support financially campaigns that are devoted to smoking cessation.

The present study has several limitations. First of all, our study sample was limited to the urban student population of Greece, living in the two biggest cities of the country. A nationwide representative sample should be considered in future surveys as well as the addition of variables exploring socio-economic status; comparison of the prevalence of exposure among students living in economically disadvantaged areas vs. economically advantaged areas and among students attending vocational school vs. those attending high school, could also be investigated.

Secondly, there was a lack of alignment with the GYTS methods, which have traditionally been used to evaluate prevalence of exposure to passive smoking by the majority of Greek and international studies. For the abovementioned reasons, the reliability of comparisons presented in this study is limited by considerable methodological differences. In particular, we used a longer time interval for evaluation of exposure and also included students aged up to about 18 years, who were found to be significantly more exposed both at home and outside compared to younger students. Therefore, it is possible that we tended to report higher rates of exposure than the GYTS-based studies. Finally, we didn't use biomarkers such as urine cotinine in order to evaluate exposure to passive smoking. Such methodology has been shown to be more accurate, since the levels of these biomarkers are strongly correlated with the amount of inhaled tobacco-smoke ${ }^{11}$.

\section{CONCLUSIONS}

Current prevalence of exposure to passive smoking among high school students in Greece is extremely high. Students are more exposed at cafes, at home and school. Gender, age, smoking status, parental, siblings' and friends' smoking habits, but also the sight of peers and teachers smoking inside the school grounds were significant determinants of students' exposure to passive smoking. The causes of such high rates of exposure are mainly the poor compliance with the New Anti- smoking Legislation that came into effect in July 2009 and the lack of tobacco-free school and home policies in Greece; thus the following issues emerge as top public health priorities. Interventions targeting students, parents and teachers should be promoted and enforcement of the antismoking legislation is imperative. Large-scale, nationwide studies are needed in order to re-assess the effectiveness of such measures.

\section{REFERENCES}

1. World Health Organization report on tobacco epidemic 2013, Geneva, Switzerland. Available from: http://who.int/tobacco/ global_report/2013/en/ (accessed 27 Oct 2015)

2. Heffernan TM, O’Neill O. Exposure to second-hand smoke damages everyday prospective memory. Addiction 2012; 108:420426

doi: 10.1111/j.1360-0443.2012.04056.x

3. Boffetta P, Trédaniel J, Greco A. Risk of Childhood Cancer and Adult Lung Cancer after Childhood Exposure to Passive Smoke: A Meta-Analysis. Environmental Health Perspectives 2000; 108:7382

doi: 10.1289/ehp.0010873

4. Besaratinia A, Pfeifer GP. Second-hand smoke and human lung cancer. Lancet Oncol. 2008; 9:657-666 doi: 10.1016/S1470-2045(08)70172-4

5. Cook DG, Strachan DP. Health effects of passive smoking, 10: Summary effects of parental smoking on the respiratory health of children and implications for research. Thorax 1999; 54:357-366 doi: $10.1136 /$ thx.54.4.357

6. Öberg M, Jaakkola MS, Woodward A, Peruga A, Prüss-Ustün A. Worldwide burden of disease from exposure to second-hand smoke: a retrospective analysis of data from 192 countries. Lancet 2011; 377(9760):139-146 doi: 10.1016/S0140-6736(10)61388-8.

7. Kyrlesi A, Sotiriades ES, Warren CW, Kremastinou J, Papastergiou P, Jones NR, Hadjichristodoulou C. Tobacco use among students aged 13-15 years in Greece: the GYTS project. BMC Public Health 2007;7:3

doi: 10.1186/1471-2458-7-3

8. Rachiotis G, Siziya S, Muula AS, Rudatsikira E, Papastergiou P, Hadjichristodoulou C. Determinants of exposure to Environmental Tobacco Smoke (ETS) among non smoking adolescents (aged 11-17) in Greece: results from the 2004-2005 GYTS Study. Int J Environ Res Public Health 2010; 7(1):284-290 doi: 10.3390/ijerph7010284.

9. Global Youth Tobacco Survey (GYTS) - World Health Organization. Available from: http://www.who.int/tobacco/ surveillance/gyts/en (accessed 27 Oct 2015)

10. Vardavas C, Klimopoulos A, Liozidou A, Behrakis P. Questionnaire design for the epidemiological study: "I learn the truth; I say no to cigarette". Biomedical Research Foundation of the Academy of Athens. Technical Report; October 2013: report number 1.2.

11. Preston AM, Rodriguez C, Rivera CE, Sahai H. Determinants of environmental tobacco smoke in a population of Puerto Rican children. Nicotine Tob Res 2001; 3:61-70 doi: 10.1080/14622200123793

12. Li MF, Wang RH. Factors related to avoidance of environmental tobacco smoke among adolescents in Taiwan. J Nurs Res 2006; 16:103-112 
Research Article

13. Rudatsikira E, Siziya S, Dondog J, Muula AS. Prevalence and Correlates of environmental tobacco smoke exposure among adolescents in Mongolia. Indian J Paediatr 2007; 74:1089-1093

ACKNOWLEDGEMENTS

The authors are

deeply thankful to

all participants, and

especially students,

teachers, school principals and personnel of the selected schools.

\section{CONFLICT OF INTEREST}

The authors have

completed and submitted

the ICMJE Form for

Disclosure of Potential

Conflicts of Interest and

none were

reported.

\section{FUNDING}

This work was supported by an ESPA grant (MIS 372829) and the George Behrakis Foundation, Boston, USA through the Hellenic Action for Research against TobaccoII project (HEART-II).

The sponsors had no contribution to the collection, analysis and interpretation of the data.

PROVENANCE AND PEER REVIEW

Not commissioned:

externally peer reviewed 